\title{
Narrativas do breu: escuridão e sombra no cinema e na dança
}

FLAVIANA XAVIER ANTUNES SAMPAIO

\section{Resumo}

O cinema preto e branco e os espetáculos de dança possuem similaridades quanto à utilização de jogos entre o claro e o escuro. Ambas as formas de arte exploram à Iluminação para criar narrativas visuais específicas. Nesta condição, conceitos de noite tendem a expressar um ambiente outro que não o 'real'. Este escrito analisa as produções fílmicas Nosferatu (1922) e L'avventura (1964) e os espetáculos de dança $L a$ Sylphide (1832) e Triz (2013), levando em consideração ideias de noite com ênfase nos conceitos de escuridão e sombra. 


\section{Narratives of pitch: darkness and shadow in the cinema and in the dance}

\begin{abstract}
Black-and-white films and dance performances have similarities in terms of the interplays of the light and the dark. Both arts explore lighting to create specific visual narratives. In this regard, concepts of night tend to express an environment outside 'reality'. This paper examines the films Nosferatu (1922) and L'avventura (1964), and the dance performances La Sylphide (1832), and Triz (2013) taking into consideration ideas of night emphasized in the exchanges conception of darkness and shadows.
\end{abstract}

Keywords:

Cinema, dance, lighting design 


\section{Las narrativas de la penumbra: la oscuri- dad y la sombra en el cine y la danza}

FLAVIANA XAVIER ANTUNES SAMPAIO

\section{Resumen}

El cine blanco y negro y los espectáculos de la danza tienen semejanzas cuanto al uso de juegos entre lo claro y lo oscuro. Las dos formas de arte explotan la iluminación para criar narrativas visuales específicas. En esta condición, conceptos como noche tienden a expresar un ambiente otro que no el 'real'. Este escrito analiza las producciones filmográficas Nosferatu (1922) y L'avventura (1964) y los espectáculos de danza La Sylphide (1832) y Triz (2013), considerando ideas como noche con énfasis en los conceptos de oscuridad y sombra. 


\section{Calada da noite}

O cinema e a dança possuem forte apelo visual por apresentarem um modo próprio de mostrar conteúdos a partir de imagens em movimento. Tais imagens funcionam como um meio de comunicação plural que possibilita diferentes reações do público. Essas estratégias se assemelham com ao que Gonçalves (2013, s./p.) define como uma 'narrativa visual' ao discutir fotografia. Nela, "o aspecto ensaístico e autoral desse tipo de fazer fotográfico ultrapassa o referente e coloca a expressão do fotógrafo, com todos os seus imateriais, dentro da imagem, provocando, desse modo, no leitor, uma aventura do sentido".

Imagine-se uma pessoa que narra para outra a ida ao cinema para assistir Dançando no Escuro (2000), de Lars Von Trier. Uma possível fala sobre o filme seria: 'A cena em que a personagem interpretada por Björk é enforcada é bastante triste'. Ainda que o narrador inclua detalhes, como o contexto do enforcamento, o ouvinte possivelmente focará atenção na imagem de uma mulher na forca porque soube que esse momento foi impactante. Paradoxalmente, outro apreciador de Dançando no Escuro pode apontar uma cena diferente como a de maior comoção demonstrando que entre a expressão da imagem e a apreciação da mesma, a interpretação do espectador é o que alicerça os possíveis significados.

$\mathrm{O}$ ato de interpretar, por sua vez, é atrelado à experiência do público e também do local e da forma o qual ele acessa uma obra. Diretores e coreógrafos valorizam as características das salas escuras para a imersão do público numa percepção peculiar. Machado (2001, p. 215) informa que a sala escura favorece a emergência de uma situação psicanalítica particular com efeito de onirismo e identificação. Tal efeito psicológico pode ser explicado a partir do viés da luz: além de explorar 
formas de revelação do espaço cênico, ela também valoriza o efeito de 'quarta parede'. Dessa forma, o distanciamento físico entre público e obra é ratificado através da escuridão da sala e também pela relação de frontalidade.

A representação da noite no cinema e na dança privilegia um ambiente diferente daquele que experienciamos ao ar livre. Isto ativa o deslumbramento do espectador quanto ao que é visto no palco ou na tela de projeção. Segundo Sorensen (2011, p. 48, tradução nossa) "na noite, podemos ver mais porque a luz do sol não invade muito nosso campo de visão". As salas de cinema e os teatros que possuem isolamento visual (caixa preta) podem ser classificadas como ambientes da noite devido à predominância da escuridão. Dito isto, o uso de luz artificial nesses espaços facilita a restrição de estímulos de imagens no campo visual ao mesmo tempo em que proporciona ao espectador a construção de sentidos estéticos.

A intensidade e brilho da(s) luz(es) também exercem um papel importante na construção das narrativas visuais. Nesta perspectiva, o cinema se distingue da dança porque a projeção de luz ocorre numa tela de modo uniforme e contínuo a direcionar o público unilateralmente. E, embora a película mostre diferentes paisagens, $o$ formato retangular com grandes dimensões é o mesmo do início ao fim. Já no caso da dança é comum o uso de diversas fontes luminosas que exploram ângulos, cores e intensidades. Aqui a noção de formato direcional não é contínua, bem como a dimensão do espaço, que se apresenta flexível. Um dançarino, por exemplo, pode ser visto isolado, em uma pequena área no fundo do palco em um momento, para em seguida ser mostrado em uma área maior, na frente, convidando o espectador a fruir a obra a partir da dinâmica não apenas do corpo em cena, mas, principalmente por causa do movimento da luz. Sendo assim, uma sensação de voyeurismo é possível porque os palcos são configurados em uma caixa de cena - ou caixa cênica - o que Nero (2009, p. 333) descreve como "o espaço cúbico onde se concentram os elementos e desenvolvem as manobras e as ações teatrais. [...]”. Esta configuração permite a criação de espaços outros através da ocultação de refletores de luz e demais aparatos, onde apenas os efeitos visuais são apresentados ao público de modo a aguçar a criatividade.

Os filmes em preto e branco são interessantes por apresentarem narrativas visuais que se distanciam das experiências humanas, usualmente baseada em cores. As películas Nosferatu (1922) e L'avventura (1964) são relevantes para análise por possuírem um tratamento de iluminação que subli- 
nha ilusões relacionadas à ideia de noite. Já os espetáculos de dança La Sylphide (1832) e Triz (2013), possuem um intervalo de três séculos, que por si permite vários pontos de conexão e diferença. Sobretudo, a seleção dessas produções também foi pautada nas possibilidades de conceitos de noite a partir da estética da luz.

\section{Noturna}

O controle da luz em produções de cinema e dança não apenas possibilita o reconhecimento de objetos, pessoas no/e espaço, como também sugere relações entre essas três informações de modo a manipular/entreter o público. Em destaque, a criação de sombra funciona não apenas para identificação do objeto/pessoa que a origina, mas explicita sentidos relacionados à temática abordada. Da mesma forma, a ausência de luz, a escuridão, também é um artifício interessante para impressão de significados em obras de cinema e dança. Entretanto, no cinema, os conceitos de sombra e escuridão estão presentes nas imagens projetadas, gravadas, enquanto que nos espetáculos de dança sob análise, esses efeitos ocorrem no palco em tempo real, ao vivo. Em ambos, as narrativas visuais apresentam sombra e escuridão como elos imprescindíveis das obras.

As produções cinematográficas que possuem apelo cronológico, que contam uma história baseada em etapas específicas de início, meio e fim, usam nuances de luz para demarcar passagem de tempo e ratificar o gênero do filme (suspense, drama, comédia etc.). Similar estratégia é vista em tradicionais espetáculos de balé clássico, os quais são baseados em libretos que por vezes narram contos de ninfas e seres inanimados. La Sylphide (1832) é um exemplo:

[...] A história trata de um espírito do bosque que se apaixona por um jovem escocês chamado James, que era comprometido. Torturado entre o real e o ideal, ele abandona sua namorada humana e foge com a sílfide. Uma feiticeira dá-lhe uma ècharpe envenenada e James, desconhecendo o fato, envolve com ela a cintura da sílfide. Porém, ao fazê-lo, suas asas caem e ela (sílfide) morre. É então levada para o céu junto às suas companheiras. James fica sozinho com sua dor [...] (PINTO, 2008, p. 45-46)

Uma semelhança entre as produções descritivas, tanto no cinema quanto no balé clássico, é a recorrência do uso da noite para conotar lugares simbólicos. O cinema preto e branco 
é uma fonte de reflexões quanto ao potencial criativo da escuridão. Em Nosferatu (1922), a noite representa as andanças de Drácula na cidade alemã de Bremen. Várias cenas desse filme expressionista retratam ambientes limitados, como quartos, a partir de marcação temporal expressa com luz reduzida. Além disso, o uso recorrente de determinado figurino dos personagens - vítimas de pijamas e Drácula com capa e vestes escuras; móveis - cama, escrivaninha; e movimentações lentas com pausas também sugerem o noturno. Jensen pontua algumas ideias quanto à exploração do uso de sombra alinhada ao exercício de interpretação do público:

Por exemplo, quando Jonathan Harker chega ao castelo um pouco antes da meia noite, a iluminação é tão brilhante que parece meio-dia. $\mathrm{O}$ espectador tem a mesma impressão quando Drácula caminha por Bremen com seu caixão, especialmente quando ele passa por uma grande árvore que produz sombra. Este tipo de sombra pode ser criado apenas com a luz do dia, logo o público tem que adivinhar que é noite pelo fato de que Drácula não pode viver durante o dia. Ao retratar erroneamente tais fatos importantes revela que deve ser difícil produzir filmes em preto e branco fazendo uma distinção entre dia e noite ${ }^{2}$ (JENSEN, 2010, p. 4, tradução nossa).

Friedrich Wilhelm Murnau, diretor de Nosferatu, impõe traços da personalidade do protagonista, um vampiro, não apenas a partir do uso recorrente de escuridão em torno dele, mas principalmente pela forma como ele é revelado. Logo, a questão da sombra é bastante crucial uma vez que o filme não possui diálogo com voz. As narrativas visuais funcionam como legenda ao tempo que são acompanhadas por música instrumental, com arranjos diversos ao sugerir tensão. Outra característica importante do filme é a aparição de frases descritivas como ligação de algumas cenas.

Um marco do jogo entre o claro e o escuro em Nosferatu é a transição de cenas a partir de efeitos de zoom. Nessa perspectiva, uma moldura circular preta parte dos extremos em direção ao centro da tela como a sugerir um blecaute. Tal estratégia, que pode ser assimilada como um 'convite' para piscar de olhos, contempla uma fruição baseada nos parâmetros de revelação, ocultação e surpresa.

L'avventura (1964) é outro filme monocromático que se destaca pelo modo que propõe jogos entre o claro e o escuro. Trata-se de um suspense que aborda o sumiço de uma mulher 
durante um passeio de barco com amigos. Aqui, embora possua um enredo diferente à Nosferatu, o uso de efeitos de sombra também acentua a ação. Na cena em que os amigos dão conta do desaparecimento de Ana em uma ilha, por exemplo, as sombras dos personagens são valorizadas assim como rochedos em relação ao mar. $\mathrm{O}$ uso de sombras propõe ainda mudanças de ambientes, como quando a caminhada de uma personagem por diferentes cômodos de uma casa é revelada inicialmente por sombras. Diferentemente de Nosferatu, L'avventura possui textos falados, sendo que alguns contêm ideias de sombra:

A cena quando a garota pergunta para o namorado sobre amor: ela diz: diga que você sente minha falta e que se pudesse você abraçaria minha sombra. Em seguida ela move seus braços e o espectador observa o movimento de sombra atrás do rapaz ${ }^{3}$ (BRUNETTE, 1998, p. 30, tradução nossa).

Sob direção do italiano Michelangelo Antonioni, L'avventura é caracterizado por revelações que perpassam o uso da sombra que não apenas atrai o espectador, mas também imprime uma ideia de originalidade. Tal artifício vai de encontro com o que Brunnette (1998) apresenta quanto ao modo de direção de Antonioni que se baseia principalmente nos efeitos visuais em oposição ao diálogo e ao enredo do personagem.

Tanto Nosferatu quanto L'avventura são exemplos de como "sombras ou sombreamentos, sendo o contraponto da luz, também são muito mais importantes em filmes em preto e branco do que em filmes coloridos" (JENSEN, 2010, p. 4, tradução nossa). Essa afirmação sugere a lógica do menos ser mais, que por vezes é aplicada em produções de dança contemporânea. Vale ressaltar que a ideia de 'menos' não é apenas fadada a algo inferior, mas também, a uma determinada quantidade de informação contrária ao 'muito', que pode conotar algo excessivo. Nesta forma de pensar, coreógrafos podem selecionar uma quantidade reduzida de material para explorar símbolos visuais e ressignificá-los no espaço, ao invés de buscar pareamento de cada ideia com um objeto ou um efeito distinto.

\section{Ausência de noite}

A dança contemporânea busca formas particulares de movimentação e uso do espaço e possui inúmeros modos de criação. Comumente, essas obras não contam histórias, mas a personalidade dos dançarinos que estão em cena. Como des- 
crito no website da companhia mineira Grupo Corpo, o espetáculo Triz (2013) foi criado a partir de estímulos advindos de uma imagem/situação:

A sensação de estar sob a mira da mitológica espada de Dâmocles, suspensa por um tênue fio de crina de cavalo, foi tão imperativa durante todo o período de gestação da mais recente obra do Grupo Corpo que acabou não apenas se impondo como o grande mote para a sua criação, mas servindo, também, de inspiração para o seu nome - Triz, palavra de sonoridade onomatopaica, que tem nos vocábulos gregos triks/ trikós (pelo, cabelo) sua mais provável origem etimológica, simbolizada pela expressão por um triz (por um fio) (s./p.).

Triz propõe efeitos visuais através da combinação de movimentos dos dançarinos que usam um macacão justo, que de um lado preto e de outro branco, - com a luz - redimensionando a área de encenação. Assim, noções de tamanho e forma geométrica são aparentes no palco como os constantes retângulos onde acontecem duos. Em cena, a subjetivação do tema é explorada em dinâmicas corporais que fazem com que o espectador experiencie a obra de modo peculiar e não uniforme.

O cenário de Triz é baseado em formas de luz, além de uma cortina longa feita de cabo de aço que emoldura o palco nas laterais e no fundo em linhas retas. A aparição dessa cortina, após vários efeitos de luz que recortam o espaço, serve como ilustração para o público indagar-se: essa cortina estava no palco desde o início do espetáculo? Qual o tamanho 'real' desse espaço?

É nesse esconde-e-revela que acontece um dos momentos mais marcantes. Dezoito bailarinos se espalham atrás do cenário enquanto três dançam na cena principal. $\mathrm{O}$ foco é nos bastidores, onde o grupo parece se aquecer e marcar a dança feita atrás. Tudo ao som de um ensaio gravado por Lenine, que deixa a plateia ouvir a contagem de passos comum na dança mas desconhecida do grande público (PAVLOVA, 2013).

Triz apresenta jogos entre o claro e o escuro de modo a sugerir que a escuridão do palco teatral por si já pode ser considerada como um espaço onírico. Ao contrário de La Sylphide que apresenta uma narrativa linear, Triz é uma obra abstrata que explora imagens em movimento sem valorizar uma definição específica de início, meio e fim. A iluminação, decerto, pontua o começo e o término do espetáculo, mas sobretudo 
transforma o espaço a partir de blecautes, efeitos de zoom e algumas sombras que norteiam o público de modo subjetivo.

A nitidez da imagem escura é afetada pelo ponto de vista do indivíduo. A quantidade de luz refletida a partir de uma superfície aumenta com o ângulo de incidência. Quando olhamos uma poça de água de cima, ela parece escura. Quando visto à distância, ela parece bastante refletida ${ }^{5}$ (SORENSEN, 2011, p. 140, tradução nossa).

Não por acaso, Triz tem sido apresentado em palcos tradicionais, estruturados por uma visibilidade frontal, onde os assentos da plateia, quando acima do nível do palco, são recuados. Desse modo, o público quando distante do local de encenação recebe estímulos visuais que os dirige a olhar para baixo e em linha reta. Constrói-se assim um ponto de convergência em que a obra é experienciada de modo similar, independentemente do local onde é vista. Segundo Danckwardt (2001, p. 219), "a plateia contemporânea, acostumada com a posição passiva nos cinemas, e principalmente na televisão, busca imagens prontas e objetivas" [...]. Ademais da estrutura das salas escuras, a iluminação cênica em espetáculos de dança é um fator decisivo para o arranjo visual, que por princípio exerce uma relação simbólica com o público. A ausência de luzes coloridas em Triz, por exemplo, sabiamente destaca o figurino do elenco. Danckwardt informa outra faceta da luz teatral em uma perspectiva mais abrangente:
Assim como o conforto dimensional dos assentos da plateia, acessos e saídas de emergência, iluminação arquitetônica, conforto térmico, acústico e de visibilidade, entre outros requisitos da audiência, também as coxias de palco, apare- lhos de iluminação, equipamentos de cenotécnica, e todos os elementos não visíveis pelo espectador devem ser objeto de atenção, entendidos como uma das partes fundamentais da experiência teatral (DANCKWARDT, 2001, p. 193).

As considerações de Danckwardt favorecem o entendimento de que criações de dança e filme precedem estudos sobre o visível e o invisível. Um exercício interessante para ambas as práticas é o arranjo de aparição e ocultação de pessoas no espaço. Essa estratégia condiciona um modo de construção artística que resulta em efeitos originais por promover imagens articuladas em um contexto macro e micro. Macro, devido às 
combinações da sequência que em conjunto expressam o cerne do trabalho e micro, por fazer com que cada imagem seja substancial à obra. Logo, o desdobramento entre o perceptível e o imperceptível é um farto caminho em busca de singularidades.

Através dos estudos em Machado é possível destacar algumas características referentes ao ato de assistir filmes que são aplicáveis ao tipo de produção de dança discutida nesse texto:

[...] O filme exige uma percepção concentrada, exclusiva e até mesmo voyeurista numa sala escura de natureza psicanalítica, isolada do mundo exterior e de todas as suas fontes de perturbação visual e auditiva. As formas expressivas do cinema se caracterizam por uma determinação ilusionista que lembra a experiência do sonho, reclamando, em consequência, recepção contínua, sem interrupções, para que não se quebre a ilusão [...] (MACHADO, 2001, p. 47).

Triz dura 40 minutos ininterruptos. La Sylphide possui dois atos intercalados. Nele, o público identifica uma nova ambientação do conto, mesmo estando livre para ter um intervalo fora da sala teatral. Inclusive, a iluminação dos assentos é ligada. Ainda assim, quando o segundo ato começa, a sensação de continuidade é provocada porque os personagens são os mesmos, embora em um ambiente diferente e também porque, em geral, os espectadores estão de posse de um programa que pontua o desenrolar da história. A interrupção entre os atos não prejudica o efeito fantasioso porque, por mais de uma vez, o espectador é imerso em uma atmosfera de fábulas. A questão do tempo por mais precisa e imutável, nessa relação palco versus plateia parece flexível e eficaz para a acomodação do público e reconhecimento de passagem de instantes dentro de uma mesma ação. Nessa perspectiva, espetáculos de dança se assimilam com o que Pantouvaki discute sobre performance:

O design do espaço dramático envolve simbolismos baseados ambos na semiologia visual e em experiência comum. Além disso, o design cenográfico cria o caráter visual da ação, que é também identificado pelas características espaciais do espaço dado. Consequentemente, quando investigamos o espaço dramático dentro de um certo espaço arquitetural, todos os elementos acima mencionados são examinados $^{6}$ (PANTOUVAKI, 2012, p. 44, tradução nossa). 
Habitualmente usamos o termo 'atemporal' para expressar algo que continua em vigor ao longo dos anos. Entretanto, essa palavra possui outro sentido quanto à forma de organização de dança e cinema. Não apenas La Sylphide, mas também nas outras três obras sob análise, a escuridão e os efeitos de sombras são usados para causar 'suspensão' e 'aceleração de tempo' em termos de localização e movimento no espaço.

Em L'avventura, a maior parte das cenas acontece dentro do barco ou na pequena ilha onde a protagonista desaparece. A delimitação do período o qual a história acontece é difícil porque os personagens usam trajes sem estampas e com corte reto, que exprimem estilo ao invés da tendência de uma determinada época. Entretanto Antonioni parece interessado na experimentação visual em detrimento das marcações em um determinado tempo, como a reprodução do dia ou da noite.

Já Nosferatu conta com efeitos ilusórios que influenciam a compreensão do filme de modo benéfico por apresentar aspectos contrastantes. Um exemplo é a constante aparição de Drácula com sombras maiores que a real, caso fosse iluminado com luz natural, o que se opõe ao enredo que tem um tom realista.

No caso de Triz, a situação difere porque não há informações lineares. Os movimentos idem em relação à predição. Aqui o espectador pode relacionar a presença da luz artificial com uma passagem da obra à noite. Essa reflexão é discutível porque, além de não trazer início-meio-fim crescentes, como se fossem crucialmente dependentes, a iluminação do espetáculo, de modo abrangente, não conota o tipo de luz que temos na noite a céu aberto (uniforme, sem contorno).

As estratégias de criação de jogos entre o claro e o escuro em produções fílmicas e de dança demandam estudos em Iluminação. Um caminho propício para artistas interessados na exploração de sombras é a seleção do material de luz e a superfície de projeção. Em Play with Light and Shadow, Schönewolf é categórica quanto à interferência da sombra em apresentações artísticas:

O jogo de sombra utiliza o tempo como um meio dramático. No seu uso irrealístico desta quarta dimensão o jogo de sombra é tão flexível como o filme. As técnicas de mistura, montagem, prolongamento de momento de tensão, e encurtamento de fases não-dramáticas geram novas possibilida$\operatorname{des}^{7}$ (SCHÖNEWOLF, 1968, p. 24, tradução nossa). 
As observações de Schönewolf colaboram para a identificação da sombra como importante material das narrativas visuais. Neste contexto, ideias de noite ou negações do noturno são possíveis através de diversas fontes de luz: lâmpada, aparelho projetor (tal qual no filme), lamparina, refletores convencionais, luz LED etc. Distante de mapear a diferença destes equipamentos, faz-se pertinente sublinhar o entendimento de que cada escolha decorre um efeito, e que experimentações com quantidade reduzida de materiais são bem-vindas, tendo em vista que há inúmeras formas de movimentações que potencializam a criação de narrativas visuais. Além disso, a combinação descuidada de fontes luminosas ou excesso de quantidade/intensidade pode causar fadiga visual ou distração do público ao invés de sugerir efeitos outros, mais próximos à temática ou objetivo do trabalho.

\section{Claro-escuro}

Nosferatu, L'avventura, La Sylphide e Triz são obras significativas na discussão de jogos entre o claro e o escuro por sugerirem metáforas que dialogam com conceitos de noite. Enquanto Nosferatu apresenta ilusões quanto ao reconhecimento da noite, L'avventura propõe cenas a céu aberto e de dia, como se a noite fosse um detalhe instável para o desenvolvimento do enredo. Por outro lado, La Sylphide utiliza ambientes sombrios que colaboram para o desenrolar da história. Em contraste, Triz possui narrativas visuais que demarcam mudanças no espaço sem evocar uma ideia precisa de noite.

As análises das quatro obras apontam que os jogos entre o claro e o escuro possibilitam efeitos estéticos originais. Ao favorecer o público ávido por novidade e singularidade, essas narrativas visuais tendem a alavancar estudos em Iluminação e mescla entre linguagens artísticas. Videodança e vídeoperformances são desenvolvidos desde o século passado. Em comum, os jogos entre o claro e o escuro podem causar diversas reações no público desde estranhamento à surpresa. Certamente essa resposta seja a mola propulsora que define empatia ou interesse do público por uma obra artística.

No que tange às estratégias de luz, a criação e produto de filmes ou de uma dança diferem entre si. O processo de construção de um filme é bastante flexível podendo integrar diversas fontes de luz desde fontes naturais, lamparina e refleto- 
res potentes, mas o produto permanece o mesmo, ocorrendo através de uma projeção uniforme. Já a iluminação de obras de dança tem laços fortes entre o processo e o produto. Se uma coreografia propõe o uso de lanternas LED, em determinado momento da criação haverá pesquisa com essa fonte de luz, mesmo que isso ocorra horas antes da estreia.

Ademais, é relevante salientar que ambas as linguagens, a cinematográfica e a da dança, adotam um profissional para pensar luz. Nas produções de dança temos o iluminador cênico e no cinema temos o diretor de fotografia. Essas terminologias são interessantes para reflexões de status e resultados. Alguns iluminadores cênicos são contratados na etapa final da montagem o que pode comprometer o conceito de luz empregado em um espetáculo de dança. Enquanto no fazer cinema, a direção de fotografia atua na ideia de imagens para o enredo do filme, o que pode validar o impacto visual positivo que as películas em geral exercem no público.

Por fim, é necessário pontuar que o desenvolvimento tecnológico tem favorecido a arte no que se refere às possibilidades de criação de narrativas visuais. A iluminação, em especial, oportuniza a ruptura de linearidade relacionada a noções de tempo e espaço. Como demonstrado, o uso de sombra e escuridão conota metáforas, fascinando o público através dos símbolos representados por imagens em movimento. A apreciação de um espetáculo de dança ou filme induz o espectador para outra atmosfera diferente daquela da sala escura antes do apagar das luzes ao adentrarem num teatro ou sala de cinema. É importante lembrar também que é possível uma tentativa de reprodução do que é visto no dia a dia nessas salas escuras, sendo que o efeito jamais é o mesmo porque a estrutura teatral e as fontes de luz são diferentes das que temos no cotidiano das ruas.
NOTAS
1. Texto original em inglês.
2. Texto original em inglês.
3. Texto original em inglês.
4. Texto original em inglês.
5. Texto original em inglês.
6. Texto original em inglês.
7. Texto original em inglês. 


\section{Referências}

BRUNETTE, Peter. The films of Michelangelo Antonioni. Cambridge: Cambridge University Press, 1998.

DANCKWARDT, Voltaire. O edifício teatral. Resultado edificado da relação palco-plateia. Porto Alegre: Programa de Pós-Graduação em Arquitetura, UFRG, 2001.

GONÇALVES, Sandra Maria Lúcia Pereira. Narrativas visuais: entre a informação e a arte. Trabalho apresentado no GT de História da Mídia Audiovisual e Visual, integrante do 9o Encontro Nacional de História da Mídia. Ouro Preto: UFOP, 2013.

GRUPO CORPO. Disponível em: <http://www.grupocorpo. com.br/obras/triz\#release>. Acesso em: 25 mar. 2015.

JENSEN, Lisa. The horror film: analysis of "Nosferatu" from 1922 to 1979. Munique: Grin Verlarg, 2010.

MACHADO, Arlindo. Máquina e imaginário: o desafio das poéticas tecnológicas. 3. ed. São Paulo: EdUSP, 2001. Disponível em: < https://books.google.co.uk/books?id=_M_Tn M8UQNwC\&printsec $=$ frontcover\&hl=pt-BR\&source $=$ gbs ge_summary_r\&cad $=0 \# \mathrm{v}=$ onepage $\& \mathrm{q} \& \mathrm{f}=$ false $>$. Acesso em: 25 mar. 2015.

NERO, Cyro Del. Máquina para os deuses: anotações de um cenógrafo e o discurso da cenografia. São Paulo: Senac, 2009.

PANTOUVAKI, Sofia. A Space within a space: contemporary scenographic approaches in Historical Theatrical Spaces. Oxfordshire: Inter-Disciplinary Press, 2012.

PAVLOVA, Adriana. A excelência do corpo em novas sensações. O Globo: 09/09/2013.

PINTO, Cinthia de A. C. Quem dança um conto aumenta um ponto: uma abordagem educacional do Romantismo para crianças com o Balé Gisele. 2008. 116 f. Dissertação (Mestrado) - Programa de Pós-Graduação em Artes Cênicas, Universidade Federal da Bahia, Salvador, 2008.

SANTANA, Ivani. Esqueçam as fronteiras! Videodança: ponto de convergência da dança na Cultura Digital. In: CALDAS, P.; BRUM, L. (Org.). Dança em foco. Dança e Tecnologia. Rio de Janeiro: Inst.Telemar. 2006. (Edição trilíngue).

SCHÖNEWOLF, Herta. Play with light and shadow: the art and techniques of shadow Theater. Tradução Alba Lerman. Nova Iorque: Reinhold Book Corporation, 1968. 
SECRETARIA DE CULTURA DO RIO DE JANEIRO. O número da sorte do Grupo Corpo. Colaboração de Juliana Krapp, 2010. Disponível em: <http://www.cultura.rj.gov.br/ materias/o-numero-da-sorte-do-grupo-corpo $>$. Acesso em: 25 mar. 2015.

SORENSEN, Roy. Seeing dark things: the philosophy of shadows. Oxford: Oxford University Press, 2011.

Recebido em: 13/05/15

Aprovado em: 05/03/16

\section{FLAVIANA XAVIER ANTUNES SAMPAIO \\ flavianasampaio@yahoo.com.br}

Doutoranda em Dança na University of Chichester (CHI) - UK. Profa.

Na Licenciatura em Dança e Licenciatura em Teatro da Universidade

Estadual do Sudoeste da Bahia (UESB). BA, Brasil. Bolsista da CAPES -

Proc n⿳0 0601/14-4. 